\title{
Crise Urbana, Legislação e Educação Ambiental
}

\author{
Crisis Urbana, Legislación e Educación Ambiental \\ Urban Crisis, Legislative and Environmental Education
}

\author{
Felipe da Silva Justo ${ }^{1}$ \\ Ana Taís Bassani ${ }^{2}$ \\ Natalia de Quadros Oliveira ${ }^{3}$ \\ Filipi Vieira Amorim ${ }^{4}$
}

\begin{abstract}
Resumo
Este artigo objetiva aproximar o Direito, a Legislação Ambiental e a Educação Ambiental. A justificativa para o estudo é a necessidade de identificar possíveis soluções para problemas atuais no que se refere a ocupações inapropriadas, ao ponto de vista jurídico-legislativo, que servem de moradia para pessoas de baixa renda, na cidade do Rio Grande/RS. Em termos metodológicos, trata-se de uma pesquisa de cunho bibliográfico que se ocupará de três momentos: um remonte histórico do surgimento aglomerados subnormais; segundo, identificará a legislação vigente para compreender as ações executadas pelo Município do Rio Grande e demais órgãos competentes; terceiro, buscará respaldo na Educação Ambiental na tentativa de interpretar os fatos e apontar possíveis soluções. O estudo conta com um aprofundamento do primeiro e segundo momento, buscando, agora, a aproximação necessária com a Educação Ambiental, motivo pelo qual torna público seu objeto de pesquisa junto ao CLAEC. Com a apresentação deste artigo, que nada mais é do que uma primeira aproximação, espera-se que outros olhares sobre a temática possam contribuir com a expansão do desenvolvimento do estudo.
\end{abstract}

Palavras-Chave: Aglomerados Subnormais. Capitalismo. Educação Ambiental. Legislação Ambiental. Ocupações.

\section{Resumen}

Este artículo tiene como objetivo aproximar el Derecho, la Legislación Ambiental y la Educación Ambiental. La justificación para este estudio es la necesidad de identificar posibles soluciones a problemas actuales, en lo que se refiere a ocupaciones inapropiadas, desde el punto de vista jurídico-legislativo, que sirven de viviendas para las personas de bajos ingresos, en la ciudad de Rio Grande/RS. En términos metodológicos, se trata de una investigación bibliográfica que se ocupará de tres partes: la primera es un remonte histórico del surgimiento de aglomerados subnormales; en el segundo, se identificará la legislación vigente para comprender las acciones ejecutadas por el Municipio de Río Grande y demás órganos competentes; y por último, en el tercero, se buscará respaldo en la Educación Ambiental, con la finalidad de interpretar los hechos y señalar las posibles soluciones. Actualmente, el estudio cuenta con una profundización de la primera y de la segunda partes, buscando la aproximación necesaria con la Educación Ambiental, motivo por lo cual se hace público su objeto de investigación junto al CLAEC. Con la presentación de este artículo, que no es más que una primera aproximación, se espera que otras miradas sobre la temática puedan contribuir con la expansión del desarrollo del estudio.

\footnotetext{
${ }^{1}$ Graduando em Direito - Universidade Federal do Rio Grande - FURG; Rio Grande, Rio Grande do Sul, Brasil; felipejusto@furg.br.

2 Pós-graduanda em Especialização em Qualificação Docente em Ciências da Natureza e Matemática Universidade Estadual do Rio Grande do Sul - UERGS; Bento Gonçalves, Rio Grande do Sul, Brasil; anabassani@uergs.edu.br.

${ }^{3}$ Mestranda em Educação em Ciências; Universidade Federal do Rio Grande - FURG; Rio Grande, Rio Grande do Sul, Brasil; natioliveira93@ hotmail.com.

${ }^{4}$ Doutor em Educação Ambiental - Universidade Federal do Rio Grande - FURG; Professor na Universidade Federal de Pelotas - UFPEL, Pelotas, Rio Grande do Sul, Brasil; filipi_amorim@yahoo.com.br.
} 
Palabras claves: Aglomerados subnormales. Capitalismo, Educación Ambiental. Legislación Ambiental. Ocupaciones.

\begin{abstract}
This article aims to approximate Law, Environmental Legislation and Environmental Education. The justification for the study is the need to identify possible solutions to current problems regarding inappropriate occupations, from the legal-legislative point of view, which serve as housing for low-income people in the city of Rio Grande/RS. In methodological terms, it is a bibliographical research that will deal with three moments: a historical reminder of the appearance of subnormal clusters; second, it will identify the legislation in force to understand the actions carried out by the Municipality of Rio Grande and other competent bodies; third, it will seek support in Environmental Education in an attempt to interpret the facts and point out possible solutions. The study counts on a deepening of the first and second moment, seeking, now, the necessary approximation with Environmental Education, which is why it makes public its research object with CLAEC. With the presentation of this article, which is nothing more than a first approximation, it is expected that other perspectives on the theme may contribute to the expansion of the study development.
\end{abstract}

Keywords: Subnormal Agglomerations. Capitalism. Environmental Education. Legislative Environmental. Ocupations.

\title{
1. Introdução
}

A cidade do Rio Grande, situada no estado do Rio Grande do Sul, assim como a maioria das cidades brasileiras, não foi devidamente planejada no ato de sua fundação. Como na maioria das urbanizações, os indivíduos se aglomeram dos centros para os entornos, conforme lhes é possível. Assim, as cidades se expandem, seus centros urbanos se definem, dá-se início à especulação imobiliária, a qual irá mensurar monetariamente o valor dos imóveis e aluguéis, e, a população com menor ou nenhum poder aquisitivo, marginalizada, acaba por ser alocada comumente em regiões mais distantes das áreas nobres da cidade, em locais denominados, segundo o IBGE (2010), como aglomerados subnormais. Conforme se verifica em grandes metrópoles, de modo explícito, e em cidades menores, de modo discreto, isso é um processo contínuo, diário e em expansão.

Insere-se neste contexto, em razão de sua situação geográfica, a cidade do Rio Grande, que em razão de suas características quanto ao crescimento desordenado e o contexto de desigualdades sociais, é facilmente percebida nas diversas ocorrências retratadas por Maricato (2011, p.18), acerca das cidades como São Paulo/SP e municípios do Estado do Rio de Janeiro/RJ, além das situações constantes dos registros das inúmeras ações cíveis e penais instauradas pelo Ministério Público Federal na comarca desta cidade. As áreas edificáveis se rivalizam com áreas de proteção permanente, numa colidência de interesses econômicos e ecológicos, gerando um conflito, ao qual se busca uma solução através da Educação Ambiental, para que a resolução desta demanda atenda aos interesses da população que habita nos aglomerados subnormais sem deixar de garantir um meio ambiente ecologicamente equilibrado, pensando-se assim, numa perspectiva socioambiental. 


\section{Crise urbana e os aglomerados subnormais na cidade do Rio Grande}

Inicialmente, é importante ressaltar as características atípicas da cidade do Rio Grande. Trata-se de uma península, cercada por águas estuarinas da Lagoa dos Patos, e assim, em meio a um frágil e importante ecossistema. Entretanto, nas últimas décadas, seguindo as premissas de crescimento mundial para países emergentes, a cidade se desenvolveu com uma velocidade maior que a capacidade da gestão do crescimento: muitos bairros e ruas sem pavimentação, escoamento pluvial, bem como a coleta de esgotos. Aliado a esses fatores, temos a carência de Estudos dos Impactos Ambientais (EIA) em relação às construções existentes, impossibilitando assim, uma atuação de forma preventiva quanto a intervenção ao meio ambiente, como prevê o Direito Ambiental Brasileiro, em seu Princípio da Precaução.

Como sabido, os recursos advindos da esfera federal e estadual são escassos e as necessidades urbanas, em contrapartida, ilimitadas. Por consequência, o rápido crescimento das cidades não consegue ser adequadamente administrado, podendo-se afirmar que vivemos uma crise urbana por conta do crescimento desordenado.

Nas palavras de Maricato (2015, p.17) "a existência das cidades precede o capitalismo". Num remonte histórico breve, no Brasil, apesar de sempre existirem as cidades, a concentração de pessoas nunca suplantou os números do campo até poucos anos atrás. Ocorreu então, uma maior imigração, destacando-se a população nordestina rumo a São Paulo, fugindo da seca, fome e dificuldades financeiras, em busca do sonho de uma vida mais digna, emprego e possibilidade de mudar suas perspectivas. O que infelizmente ocorreu foi a manutenção da miserabilidade desses indivíduos, que acabam marginalizados e subutilizados como mão de obra barata.

Observadamente, Maricato (2015, p.22) aponta que os capitais, em cada momento histórico e conforme os ciclos econômicos, almejam, de modo articulado, moldar as cidades conforme suas conveniências, numa aliança. Entretanto, como todo processo histórico, existem inúmeros fatores que, de modo contrário ou favorável, direcionam, guiam, e algumas vezes, até freiam os investimentos e avanços, de modo contraditório, mas não incomum, haja vista as dissonâncias dos objetivos dos grupos que conduzem e administram os interesses do mercado, nas suas inúmeras facetas e agentes. Entretanto, como referido pela autora, algumas vezes esses agentes acabam por ter interesses diversos, a exemplo, os promotores imobiliários e proprietários de terras que possuíam interesses contrários aos capitais industriais, como acontecido em alguns momentos marcantes da história das cidades dos países centrais do capitalismo. Claro que essas colidências podem advir de outros acontecimentos, como a luta social por melhores salários, condições de trabalho e de vida. Na busca por melhores 
condições, os agentes humanos dos centros urbanos acabam por pressionar e serem vistos como uma parcela do mercado que possui poder de compra, gerando, uma acirrada disputa de sobrevivência, resultando na segregação daqueles incapazes de se manterem produtivos e rentáveis. É a seleção natural do capitalismo.

\section{Leis Federais e Resoluções CONAMA}

As construções de moradias, em locais denominados aglomerados suburbanos, em Áreas de Proteção Ambiental (APAs), configura crime de dano ao meio ambiente, conforme a disposto na Lei 9.605 (BRASIL, 1998), embora a moradia se configure um direito fundamental, conforme o exposto no artigo $6^{\circ}$ da Constituição Federal (BRASIL, 1988), que trata dos direitos sociais "são direitos sociais a educação, a saúde, a alimentação, o trabalho, a moradia, o transporte, o lazer, a segurança, [...] na forma desta Constituição.”

Apesar da instituição do Código Florestal (BRASIL, 1965) na década de 60, as Áreas de Proteção Ambiental somente foram ampliadas pelas proteções que a Medida Provisória $\mathrm{n}^{\circ}$ 2166-67 (BRASIL, 2001) trouxe, e, devidamente reguladas pela Resolução no 303/2002, editada pelo Conselho Nacional do Meio Ambiente - CONAMA, que objetivava regulamentar o previsto no artigo $2^{\circ}$ da Lei $n^{\circ}$ 4.771/1965. A Resolução 303 (CONAMA, 2002) definiu e delimitou as Áreas de Preservação Permanente (APPs), sendo posteriormente, flexibilizada em alguns dos critérios pela Resolução no 369 (CONAMA, 2006), que permitiu a intervenção ou supressão de vegetação nas Áreas de Preservação Permanente, desde que fossem respeitadas as hipóteses e os parâmetros nela exarados.

Assim, à luz dos mais recentes posicionamentos socioambientais e conforme a doutrina pátria prolata em literatura jurídica, além da percepção por parte dos aplicadores da Lei, vem se construindo um entendimento, ainda que moroso em relação à quantidade de situações que ocorrem por todos os tribunais do país: a remoção forçada dos ocupantes de áreas de preservação permanente não resolve o problema, apenas agrava mais a questão. Assim, o Ministério Público Federal, no âmbito de sua atuação, como fiscal da Lei e ordem pública, vem percebendo a sua impotência em gerir esses casos, seja pela elevada demanda de atuação em uma questão que só afeta o próprio invasor sem reverter em benefício ou melhoria à sociedade, seja pela ineficácia da atuação, dado que as ocupações são contínuas, de forma que ao desocupar o terreno, apenas permite que outra pessoa, de situação similar ao ulterior expulso, ocupe o lugar.

Apesar da garantia consolidada no Artigo $6^{\circ}$ da Carta Constitucional (BRASIL, 1988), em um país de desigualdades, prevalece a aplicação dura da Lei, mas como dito, a mão do 
Estado pesa mais onde há maior fragilidade e vulnerabilidade social. Para melhor se delimitar a compreensão, a cidade do Rio Grande, objeto de estudo neste trabalho, é cercada por Áreas de Preservação Permanente, que segundo o Mapa de Biomas do Brasil (IBGE, 2004), se localiza em Bioma do Pampa, entretanto, o ecossistema em que está inserida a área está incluído no Bioma de Mata Atlântica, conforme o Mapa da Área de Aplicação da Lei no 11.428 (BRASIL, 2006).

\section{Educação Ambiental transformadora}

Segundo projeções da Organização das Nações Unidas - ONU (United Nations - UN, 2014), em 2020, o Brasil será composto por aproximadamente $88 \%$ de população urbana e $12 \%$ na área rural, e essa diferença irá aumentar ainda mais, como os dados exemplificam: em 1960 a população rural era de 40 milhões e a urbana 15 milhões, mas em 2016, a população rural se reduziu para 29 milhões, e população urbana salta, exponencialmente, para 178 milhões. Posta esta projeção, sem dúvidas, aterrorizante, que demonstra o inchaço extremo das zonas urbanas, trazendo toda uma problemática, poluição, esgotamento de recursos, propagação de doenças, danos ao solo, uma selva de concreto, que exclui as demais espécies, animais e vegetais, o que é demonstrado por Guimarães (1995, p. 12) quando discorre sobre o homem e a natureza:

Nas sociedades atuais o ser humano afasta se da natureza. [...] $\mathrm{O}$ ser humano, totalmente desintegrado do todo, não percebe mais as relações de equilíbrio da natureza. Age de forma totalmente desarmônica sobre o ambiente, causando grandes desequilíbrios ambientais [...].

Com essa compreensão do agir dos homens e mulheres da nossa sociedade, baseado nesse modelo de consumo desenfreado, que promovia um esgotamento dos "recursos", percebeu-se o risco que o planeta, e por consequência, a espécie humana, corria, de forma que novas propostas surgiram, visando a "preservação", mas apenas para garantir o consumo, e através disso, desencadear o aumento das desigualdades, pois apenas uma fração de pessoas usufrui com os lucros que adimplidos nessa exploração desenfreada. Isto por que as formas de poluição são diversas, e cada agente contribui de um modo, nas capacidades que lhe cabem, de forma que é absurdo comparar uma mineradora poluidora com um pequeno pescador que enceta sua atividade em período proibido (defeso): são atividades que poluem e afetam o equilíbrio natural, mas devem ser observadas em perspectivas baseadas na proporcionalidade do dano, como aponta Reigota (2009, p. 50) acerca dessa situação: 
Os impactos ambientais que provocamos com o nosso estilo de vida são diferentes e diferenciados e precisam ser enfatizados e não camuflados na afirmativa simplificadora de que "o homem destrói o meio ambiente". (grifo do autor).

Assim, apontando como questão de basilar da Crise Urbana, que enseja o surgimento dos aglomerados subnormais (IBGE, 2010) em decorrência do crescimento desordenado, desorganizado e desenfreado das cidades, além das desigualdades surgidas nesse processo, como observa Maricato (2015), em que o mercado residencial legal brasileiro atende algo em torno de $30 \%$ da população brasileira, deixando de fora, em algumas cidades, até mesmo os indivíduos da classe média que recebe de cinco a sete salários mínimos, que sem opção, devido às dificuldades para o ingresso nesse mercado imobiliário, restando aos outros $70 \%$ apenas o caminho da ilegalidade, ou seja, invadir áreas de ecossistema frágil protegidas por legislação ambiental, tais como mananciais, mangues, várzeas, encostas, beira de córregos, locais de mata nativa e dunas.

\subsection{A Crise Urbana e políticas públicas pautadas na Educação Ambiental}

O problema de estudo, fundado nas assertivas e respaldo que a Educação Ambiental proporciona na busca pela elucidação do paradigma da crise urbana, causadora da formação dos aglomerados urbanos, é algo que importa ser observado, em decorrência da modernidade atual, do aumento da população e por consequência, uma maior ameaça ao meio ambiente equilibrado.

Apesar das políticas públicas, em sede mundial, com acordos e tratados para diminuição de emissões de gases, de queima de combustíveis fósseis e atividades econômicas potencialmente poluidoras, a verdade é que tais tratativas passam longe da sociedade comum, os indivíduos que vivem em condições modestas ou daí para alcançar os aglomerados subnormais, não é um beneficiário direto dessas políticas. A razão de tal alegação se baseia nas críticas à própria legislação ambiental, que apesar de possuir uma essência protetiva, não resolve os problemas que uma grande parte da população, pois mesmo os que não vivem em aglomerados subnormais, ainda são afetados pela crise urbana, que onera a sociedade em vários ambitos, seja pelo aumento da criminalidade, propagação de doenças, sobrecarga dos serviços de transportes e outros. O que leva essa afirmação, trágica, mas real, é a gritante desigualdade social que se verifica na atualidade: Nunca houve tantos sem nada e pouquíssimos com tanto. Isso exposto, o que se tem é uma sociedade que, sem um amparo da Educação Ambiental, através de políticas públicas fundadas em pautas consistentes com as necessidades da população em estado de precariedade. 


\subsection{Construção de uma racionalidade ambiental diante o paradigma da Crise Urbana}

Numa perspectiva baseada na Educação Ambiental, para, ao propor caminhos, equalizar as dicotomias existenciais da nossa contemporaneidade, na premissa de que o meio ambiente deve ser objeto de proteção, sempre, mas não pode ser utilizado como meio de aumento das desigualdades, quando da aplicação das legislações protetivas. Isso não pode ser deixado de lado ou esquecido pelos operadores do direito, políticos, agentes do mercado econômico, além de que, quando ocorrer fiscalização pelo Estado, deve ser de modo eficiente, afim de que a legislação, que deve objetivar um meio ambiente equilibrado, não cause um aumento das desigualdades, e por consequência, mais degradação. A razão de afirmar isso se baseia em um fato simples: o ser humano é potencialmente poluidor. Qualquer aglomeração de indivíduos, baseados em consumo, geram poluição, e quando não há a presença do Estado, garantindo serviços básicos para essa população, como é o que ocorre nos aglomerados subnormais, temos um aumento significativo da degradação ambiental.

Apesar da desigualdade não afetar a parcela economicamente estável da sociedade, pois estes estão "protegidos" em suas residências seguras, onde há serviços de qualidade, prestados pelo Estado (água, tratamento de esgoto, coleta de lixo, segurança) ou por vezes, pagos pela própria iniciativa privada, tem-se a necessidade de pontuar um fato único: todos compartilham um mesmo planeta, de forma que o alto padrão de vida causa impactos ambientais, mesmo que não alcancem a mesma visibilidade dos impactos ambientais produzidos e percebidos pelos moradores dos aglomerados subnormais.

O humano, numa crise de vínculo, se tornou incapaz de perceber o que o liga ao animal, à natureza, embora este indivíduo seja incapaz de existir sem aquilo (animais e natureza) que não lhe é percebido, o que resulta a atual crise socioambiental, como evidenciado por François Ost (1995, p.9). Dessa forma, necessita-se, através da Educação Ambiental, a instauração de uma nova racionalidade, a racionalidade ambiental, que estabeleça um pensamento organicista, de reconhecimento ao mundo a que pertencemos, como seres dependentes, que demonstre a nossa necessidade de buscar e manter um equilíbrio ecológico.

\section{Considerações}

Importante explicitar que a cidade do Rio Grande, com sua formação peninsular possui um afastamento dos seus bairros, em razão da sua formação geográfica, uma vez a zona mais nobre da cidade não possui condições de se expandir, restando então que os indivíduos se afastem dela, buscando locais cada vez mais distantes, objetivando alugueis e 
custo de vida mais conveniente, aliado as dificuldades econômicas que a cidade vem passando, em razão da extinção de inúmeros postos de trabalho, o que resulta no grave quadro apontado, ou seja, disparadas invasões em áreas com fragilidade ambiental, que carecem de proteção por parte do estado.

Assim, como tratado no presente trabalho, pode se verificar que há muito mais além de "meras ocupações", pois estas indicam, de modo claro, tal qual um termômetro, o "aquecimento" das zonas periféricas, algo que pode ser visto a olho nu, na cidade do Rio Grande, onde se localiza o Corredor do Leopoldo, objeto desse estudo. Observadamente, o intuito é para além da mera crítica aos agentes que participaram e produziram a atual situação existente no Corredor do Leopoldo, visando compreender todo o aspecto socioeconômico que refletiu tal resultado.

Por isso é importante buscar compreender a cidade como um ente vivo, composta de seres humanos, muito além do marketing urbano praticado pelo mercado imobiliário, e que através de uma atuação do poder público amparada na lisura, permitindo que os agentes que compõem a cidade, no seu todo, possam participar e ter voz nas decisões, tal qual buscou-se praticar em algumas cidades brasileiras, através do Orçamento Participativo, que desvinculava o poder de decisão dos lobbies, do mercado imobiliário e especulativo, e alcançando os reais e verdadeiros componentes da cidade.

Assim, através de uma política inclusiva, participativa, construída pelo e para os moradores e moradoras da cidade, se alcançar uma melhora na qualidade de vida, no âmbito habitacional, com melhorias na infraestrutura, disponibilidade de saneamento básico, coleta de lixo, iluminação, transporte público que integre essas regiões com as zonas nobres, permitindo um melhor fluxo de movimentação, pois uma cidade deve incluir e garantir a inclusão.

Deste modo, percebe-se necessidade e a importância da Educação Ambiental buscar alcançar objetivos como a conscientização dos indivíduos e grupos, proporcionando-lhes o apropriado conhecimento (não apenas técnico-científico, mas também os saberes populares como uso de chás e ervas medicinais, por exemplo - acerca da natureza que os circunda) para uma atuação individual e coletiva cotidianas, como aponta Reigota (1996, p. 18 e 19)

A educação ambiental deve orientar-se para a comunidade, para que ela possa definir quais são os critérios, os problemas e as alternativas [...] auxiliar e incentivar o cidadão e a cidadã a participarem da resolução dos problemas e da busca de alternativas no seu cotidiano de realidades específicas [..] influir decisivamente para isso, quando forma cidadãos e cidadãs conscientes dos seus direitos e deveres. Tendo consciência e conhecimento da problemática global e atuando na sua 
comunidade e vice-versa haverá uma mudança na vida cotidiana que, se não é de resultados imediatos, visíveis, também não será sem efeitos concretos.

Essas práticas, baseadas na valoração e no hábito de se procurar fazer sempre o melhor, proporciona o desenvolvimento de competências para tratar da resolução das demandas ambientais locais, assim como desenvolver um olhar crítico para os "avanços" da ciência pró-capital, participando de modo ativo e consciente dos impactos que as ações humanas causam no equilíbrio ecológico do Planeta e que, igualmente, o crescimento das cidades é um exemplo vivo e próximo de todos, pois não há quem não seja afetado pelas consequências que esse problema causa.

$\mathrm{O}$ ideal que se persegue é que o conhecimento produzido possa alcançar aqueles que são objeto do estudo, para além das meras deliberações no "mundo das ideias", pois como coloca Reigota (2016, p. 19), o homem e a mulher criam os problemas ambientais e lhes compete buscar a devida solução, não sendo possível delegar essa competência (apenas) para a ciência, políticos ou até mesmo para a vizinha ou o vizinho.

Assim, através de uma política inclusiva, participativa, construída com e para os moradores e as moradoras das cidades (sejam de zona urbana ou rural), pode-se alcançar uma melhora na qualidade de vida, no âmbito habitacional, com melhorias na infraestrutura, disponibilidade de saneamento básico, coleta de lixo, iluminação, transporte público que integre essas regiões com as zonas nobres, permitindo um melhor fluxo de movimentação. Justifica-se essa afirmação com o fato de que a cidade deve garantir a inclusão, pois é competência e dever dos entes do poder público garantir um meio ambiente saudável e pleno a toda sociedade, tal como exposto no artigo 225 da Constituição Federal (BRASIL, 1988), mas também - e isso deve ser sempre balanceado e sopesado -, mediante o exposto nos artigos 182 e 183 da Carta Constitucional, que tratam acerca da política urbana, plano diretor e da necessidade da propriedade urbana atender a sua função social.

Obviamente, esse processo é algo que deve ser construído, adequando as realidades e peculiaridades de cada região, através das ferramentas administrativas disponíveis aos municípios, órgãos fiscalizadores, associações de moradores, e outras entidades sociais, assim como, através da academia, possibilitando que esse potencial seja utilizado para a construção de um diálogo entre os vários elementos que compõem a área urbana e rural das cidades, em um trabalho conjunto para proporcionar ao máximo de pessoas os benefícios de natureza pública. A Educação Ambiental, ao propor caminhos e soluções para a resolução de demandas como as especificadas neste anteprojeto, pode auxiliar na fiscalização das atividades dos agentes do poder público, no intuito de coibir afrontas ao frágil equilíbrio entre cidade 
urbanizada e meio ambiente, inovando em suas competências e buscando a construção de outros lugares possíveis ao alcance todos.

\section{Referências}

BRASIL. Lei $\mathbf{n}^{\mathbf{0}}$ 4.771, de 15 de setembro de 1965. Institui o novo Código Florestal. Disponível em: http://www.planalto.gov.br/ccivil_03/leis/L4771.htm Acesso em: 28 ago. 2017.

BRASIL. Constituição da República Federativa do Brasil de 1988. Disponível em: http://www.planalto.gov.br/ccivil_03/constituicao/constituicao.htm Acesso em: 28 ago. 2017.

BRASIL. Lei n 9.099, de 26 de setembro de 1995. Dispõe sobre os Juizados Especiais Cíveis e Criminais e dá outras providências. Disponível em:

http://www.planalto.gov.br/ccivil_03/leis/L9099.htm Acesso em: 28 ago. 2017.

BRASIL. Lei $\mathbf{n}^{\circ}$ 9.795, de 27 de abril de 1999. Dispõe sobre a educação ambiental. Disponível em: http://www.planalto.gov.br/ccivil_03/Leis/L9795.htm. Acesso em 11 nov. 2017.

BRASIL. Lei $\mathbf{n}^{\mathbf{0}}$ 9.985, de 18 de julho de 2000. Regulamenta o art. 225, § $1^{\circ}$, incisos I, II, III e VII da Constituição Federal, institui o Sistema Nacional de Unidades de Conservação da Natureza e dá outras providências. Disponível em:

http://www.planalto.gov.br/ccivil_03/leis/L9985.htm Acesso em: 28 ago. 2017.

BRASIL. Lei no 10.257, de 10 de Julho de 2001. Regulamenta os artigos 182 e 183 da Constituição Federal, estabelece diretrizes gerais da política urbana e dá outras providências. Disponível em: http://www.planalto.gov.br/ccivil_03/leis/LEIS_2001/L10257.htm. Acesso em: 20 set. 2017.

BRASIL. Lei $\mathbf{n}^{\mathbf{0}} \mathbf{1 1 . 4 2 8}$, de 22 de dezembro de 2006. Dispõe sobre a utilização e proteção da vegetação nativa do Bioma Mata Atlântica, e dá outras providências. Disponível em:

http://www.planalto.gov.br/ccivil_03/_ato2004-2006/2006/lei/111428.htm Acesso em: 28 ago. 2017.

BRASIL. Lei $n^{\mathbf{0}}$ 13.240, de 30 de dezembro de 2015. Dispõe sobre a administração, a alienação, a transferência de gestão de imóveis da União e seu uso para a constituição de fundos; altera a Lei no 9.636, de 15 de maio de 1998, e os Decretos-Lei nos 3.438 , de 17 de julho de 1941, 9.760, de 5 de setembro de 1946, 271, de 28 de fevereiro de 1967, e 2.398, de 21 de dezembro de 1987; e revoga dispositivo da Lei n⿳0 13.139 , de 26 de junho de 2015. Acesso em: 28 ago. 2017.

BRASIL. Medida Provisória no 2.166-67, de 24 de agosto de 2001. Altera os arts. $1^{\circ}, 4^{\circ}$, 14, 16 e 44, e acresce dispositivos à Lei no 4.771, de 15 de setembro de 1965, que institui o Código Florestal, bem como altera o art. 10 da Lei no 9.393, de 19 de dezembro de 1996, que dispõe sobre o Imposto sobre a Propriedade Territorial Rural - ITR, e dá outras providências. Disponível em: http://www.mma.gov.br/port/conama/legiabre.cfm?codlegi=368 Acesso em: 28 ago. 2017. 
CONAMA. Resolução No 303/2002. Dispõe sobre parâmetros, definições e limites de Áreas de Preservação Permanente. Data da legislação: 20/03/2002. Publicação DOU nº 090, de 13/05/2002, pág. 068. Disponível em:

http://www.mma.gov.br/port/conama/legiabre.cfm?codlegi=299 Acesso em: 28 ago. 2017.

CONAMA. Resolução No 369/2006. Dispõe sobre os casos excepcionais, de utilidade pública, interesse social ou baixo impacto ambiental, que possibilitam a intervenção ou supressão de vegetação em Área de Preservação Permanente - APP. Data da legislação: 28/03/2006. Publicação DOU no 061, de 29/03/2006, págs. 150-151. Disponível em: http://www.mma.gov.br/port/conama/legiabre.cfm?codlegi=489

COURB. O que é Gentrificação e por que você deveria se preocupar com isso. Acesso em 20 de nov. 2017. Disponível em: http://www.courb.org/pt/o-que-e-gentrificacao-e-por-quevoce-deveria-se-preocupar-com-isso/

GUIMARÃES, Mauro. A Dimensão Ambiental na Educação. Campinas: Papirus, 1995. IBGE. Mapa de Biomas e de Vegetação. Disponível em:

http://www.ibge.gov.br/home/presidencia/noticias/21052004biomashtml.shtm Acesso em: 28 ago. 2017.

IBGE. Censo demográfico: 2010: aglomerados subnormais: informações territoriais. Disponível em: https://biblioteca.ibge.gov.br/pt/biblioteca-catalogo?view=detalhes\&id=7552. Acesso em: 20 set. 2017.

IBGE. Cidades. Disponível em: https://cidades.ibge.gov.br/brasil/rs/rio-grande/panorama. Acesso em: jul. 2013.

MARICATO, Erminia. O impasse da política urbana no Brasil. Petrópolis, RJ: Vozes, 2011.

MARICATO, Erminia. Para Entender a Crise Urbana. São Paulo: Expressão Popular, 2015.

OST, François. A natureza a margem da lei: ecologia à prova do direito. Lisboa: Instituto Piaget, 1995.

REIGOTA, Marcos. O que é educação ambiental. São Paulo: Brasiliense, 2009.

UNITED NATIONS. Department of Economic and Social Affairs, Population Division (2014): World Urbanization Prospects - The 2014 Revision. Disponível em: https://esa.un.org/unpd/wup/Country-Profiles/ Acesso em: 18 nov. 2017. 